\title{
BMJ Open A retrospective review of paediatric head injuries in Asia - a Pan Asian Trauma Outcomes Study (PATOS) collaboration
}

\author{
Shu-Ling Chong, ${ }^{1,2}$ Uzma Rahim Khan, ${ }^{3}$ Indumathy Santhanam, ${ }^{4}$ Jun Seok Seo, ${ }^{5}$ \\ Quan Wang, ${ }^{6}$ Sabariah Faizah Jamaluddin, ${ }^{7}$ Quoc Ai Hoang Trong, ${ }^{8}$ \\ Su Yah Chew, ${ }^{9,10}$ Marcus Eng Hock Ong ${ }^{11,12}$
}

To cite: Chong S-L, Khan UR, Santhanam I, et al. A retrospective review of paediatric head injuries in Asia - a Pan Asian Trauma Outcomes Study (PATOS) collaboration. BMJ Open 2017;7:e015759. doi:10.1136/ bmjopen-2016-015759

- Prepublication history and additional material for this paper are available online. To view these files please visit the journal online (http://dx.doi. org/10.1136/bmjopen-2016015759).

Received 30 December 2016 Revised 17 May 2017 Accepted 29 June 2017

CrossMark

For numbered affiliations see end of article.

Correspondence to

Shu-Ling Chong;

chong.shu-ling@kkh.com.sg

\section{ABSTRACT}

Objective We aim to examine the mechanisms of headinjured children presenting to participating centres in the Pan Asian Trauma Outcomes Study (PATOS) and to evaluate the association between mechanism of injury and severe outcomes.

Design and setting We performed a retrospective review of medical records among emergency departments (EDs) of eight PATOS centres, from September 2014 - August 2015.

Participants We included children $<16$ years old who presented within 24 hours of head injury and were admitted for observation or required a computed tomography (CT) of the brain from the ED. We excluded children with known coagulopathies, neurological co-morbidities or prior neurosurgery. We reviewed the mechanism, intent, location and object involved in each injury, and the patients' physical findings on presentation.

Outcomes Primary outcomes were death, endotracheal intubation or neurosurgical intervention. Secondary outcomes included hospital and ED length of stay.

Results 1438 children were analysed. 953 children (66.3\%) were male and the median age was 5.0 years (IQR 1.0-10.0) Falls predominated especially among children younger than 2 years $(82.9 \%)$, while road traffic injuries were more likely to occur among children 2 years and above compared with younger children ( $25.8 \%$ vs $11.1 \%$ ). Centres from upper and lower middle-income countries were more likely to receive head injured children from road traffic collisions compared with those from high-income countries $(51.4 \%$ and $40.9 \%$, vs $10.9 \%, p<0.0001$ ) and attended to a greater proportion of children with severe outcomes ( $58.2 \%$ and $28.4 \%$, vs $3.6 \%, p<0.0001)$. After adjusting for age, gender, intent of injury and gross national income, traffic injuries (adjusted OR $2.183,95 \% \mathrm{Cl} 1.448$ to 3.293 ) were associated with severe outcomes, as compared with falls.

Conclusions Among children with head injuries, traffic injuries are independently associated with death, endotracheal intubation and neurosurgery. This collaboration among Asian centres holds potential for future prospective childhood injury surveillance.
Strengths and limitations of this study

- In this pioneer collaboration, mechanisms of head injury and patient outcomes were compared between diverse centres in Asia.

- Data were obtained through a common electronic platform using a standardised form.

- Heterogeneity in trauma documentation exists among different centres.

- We presented hospital-based clinical data because national data of this nature are not available in many countries in Asia, where trauma databases are being established.

\section{INTRODUCTION}

Childhood injury remains a regrettable source of premature death and disability worldwide. Despite the progress made in injury prevention, the scale of paediatric trauma remains significant. ${ }^{1}$ According to WHO autopsy reports, up to a quarter of deaths from external causes occurred in children younger than 15 years old. ${ }^{2}$ These were dominated by transport-related injuries in many parts of Asia and Africa, ${ }^{2}$ where fatalities and injuries from road traffic collisions are increasing. ${ }^{3}$

Paediatric head injuries are critically important because of the high mortality risk. ${ }^{4}$ Among survivors, the potential for lifelong neurological devastation could mean years of lost productivity, compromised quality of life and dependence on others for activities of daily living. ${ }^{5}$ Severe traumatic brain injury slows down processing speed and adaptive functioning in the long term. ${ }^{67}$ These irreversible effects are keenly felt by the child, the family and society at large.

A significant proportion of severe paediatric head injuries occur in Asia, yet surveillance in this region remains inadequate. In this 


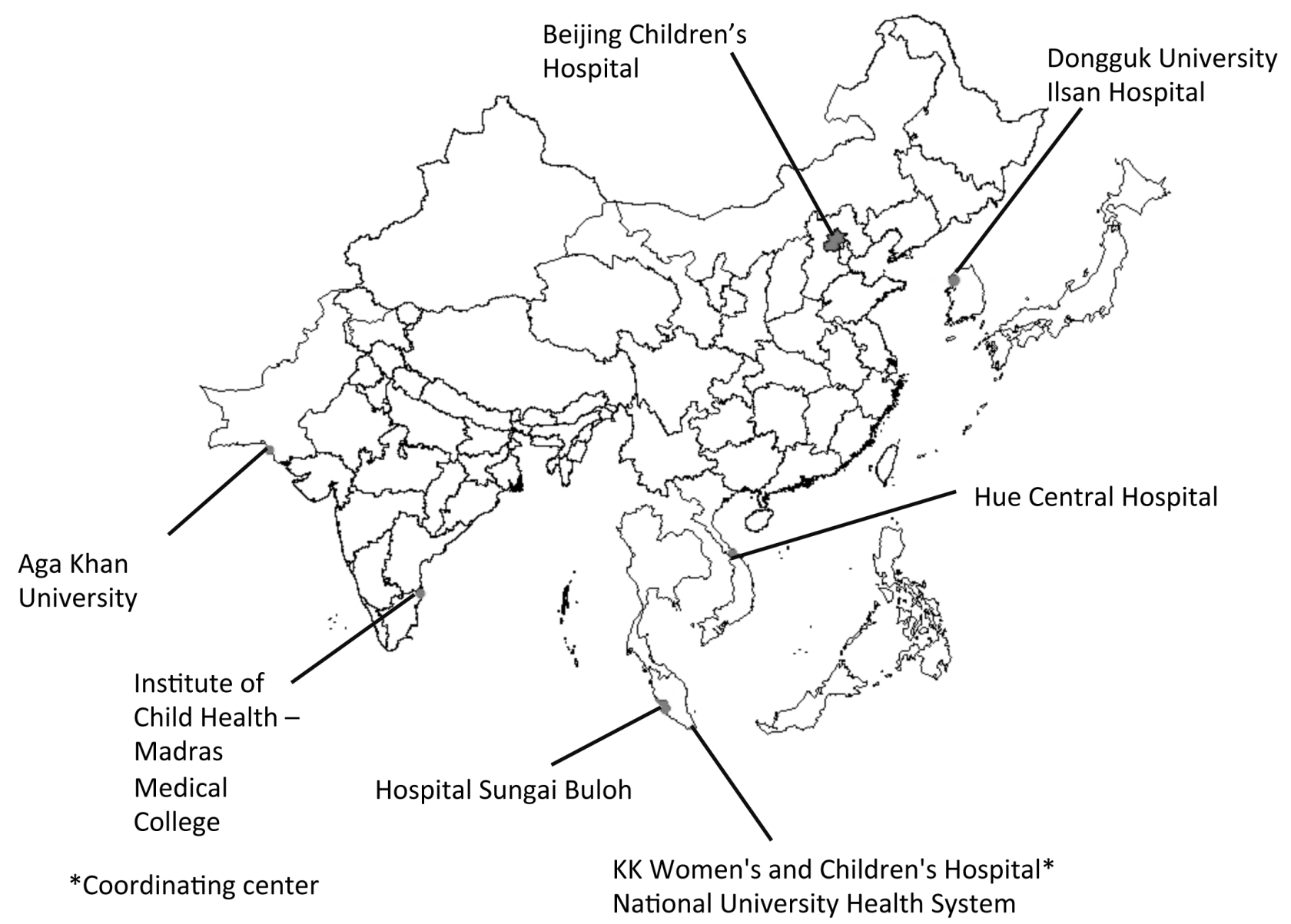

Figure 1 Map of participating Pan Asian Trauma Outcomes Study (PATOS) centres.

multicentre study, we aim to: (1) Examine the injury epidemiology of children presenting with head injuries to participating centres in the Pan Asian Trauma Outcomes Study (PATOS), specifically comparing children younger than 2 years to children 2 years and older, and (2) Study the association between the mechanism of injury and severe outcomes as defined by death, the need for endotracheal intubation and neurosurgical intervention.

\section{MATERIALS AND METHODS \\ Design and setting}

This was a retrospective chart review performed in participating centres of PATOS between September 2014 to August 2015. PATOS is an Asian clinical research network with a multicentre trauma registry. ${ }^{8}$ Centres participated in this study on a voluntary basis and are from the following countries: Singapore, Pakistan, India, South Korea, China, Malaysia and Vietnam. (figure 1) Countries were grouped into lower middle, upper middle and high-income economies by per capital gross national income (GNI) based on the World Bank classification. ${ }^{9}$ The data collection was performed in a uniform fashion using a standardised electronic data form with the variables explored a priori for common understanding.
Ethics approval was obtained for each centre, with the coordinating centre obtaining approval from the Singapore Singhealth Centralised Institutional Review Board (CIRB, E).

\section{Patients}

We included children $<16$ years old who presented within 24 hours of head injury and were admitted for observation or required a computed tomography (CT) of the brain from the emergency department (ED). Patients with known coagulopathies, prior neurosurgery, neurological deficits or developmental delay were excluded. The presence of neurological deficits or developmental delay was determined by the attending ED physician. We chose to exclude the above patients because of increased complexity in neurological assessment and different thresholds for investigations and hospitalisation. We also excluded trivial injuries in children whose symptoms had resolved while in the ED and who did not clinically warrant further monitoring or investigations. Patients with a low Glasgow Coma Scale (GCS) score (13 and below) or with persistence of symptoms including headache or vomiting underwent a CT head scan (at the physician's discretion). In cases of polytrauma, we confirmed that the low GCS was due to head trauma, as evidenced by a positive CT 
consisting: intracranial bleed, cerebral oedema, diffuse axonal injury or skull fracture. In the case of death, the post mortem must have proven an intracranial injury for the patient to be included.

\section{Variables}

We followed the International Classification of External Causes of Injury (ICECI) classification ${ }^{10}$ and established common data points across the PATOS centres. The primary mechanism of injury was collected for all patients, including the following: Fall, road traffic injury, struck by object or person, sports injury, gunshot or others. For falls, the height of the fall was documented. In the case of road traffic injuries, the injured person type (pedestrian, cyclist, motor vehicle passenger, motorbike user) and the use of preventative measures (helmets, child car seats or seat belts) were collected. The intent of injury describes if the child was involved in an unintentional injury, intentional self-harm, assault or if the intent was unknown. Specifically for assault, we differentiated child abuse cases by caregivers from other forms of assault that occurred in schools or by strangers. The object involved in the trauma (including ground surface, furniture or land transport) and the location of occurrence (home, school, public road, sports area or playground) was also recorded. The patient's presenting GCS and physical examination findings were documented.

\section{Main outcome measures}

The primary outcome measures were: Death, need for endotracheal intubation or neurosurgical intervention. ${ }^{11}$ We also reviewed the hospital and ED length of stay.

\section{Analysis}

Categorical data were presented as frequencies and percentages. Continuous data were presented using means (with $\mathrm{SD}$ ) or medians (with interquartile ranges, IQR), depending on normality of distribution. We analysed children $<2$ years versus children 2 years and older separately, recognising that younger children are preverbal, have evolving ambulatory skills and are predisposed to different mechanisms of injury. ${ }^{12}$ Measures of association between the outcomes and categorical variables were analysed using Chi Square test or Fisher's Exact test, while that of continuous variables were analysed using either Student t-test or Mann Whitney U, depending on normality. For predictors with multiple categories, the Kruskal-Wallis test was used. Statistical significance was established at $\mathrm{p}<0.05$. A univariable logistic regression was performed to establish the association between the mechanism of injury and severe outcomes. In the multivariable logistic regression, we adjusted for age, gender, intent (unintentional, intentional or unknown), mechanism of injury (fall, road traffic injury, struck by person or object, or others) and GNI group. For the regression, we presented each point estimate with its 95\% CI. Data were analysed using IBM SPSS Statistics Version 19.0. SPSS Inc, Chicago.
8324 children $<16$ years old

presenting with head injuries

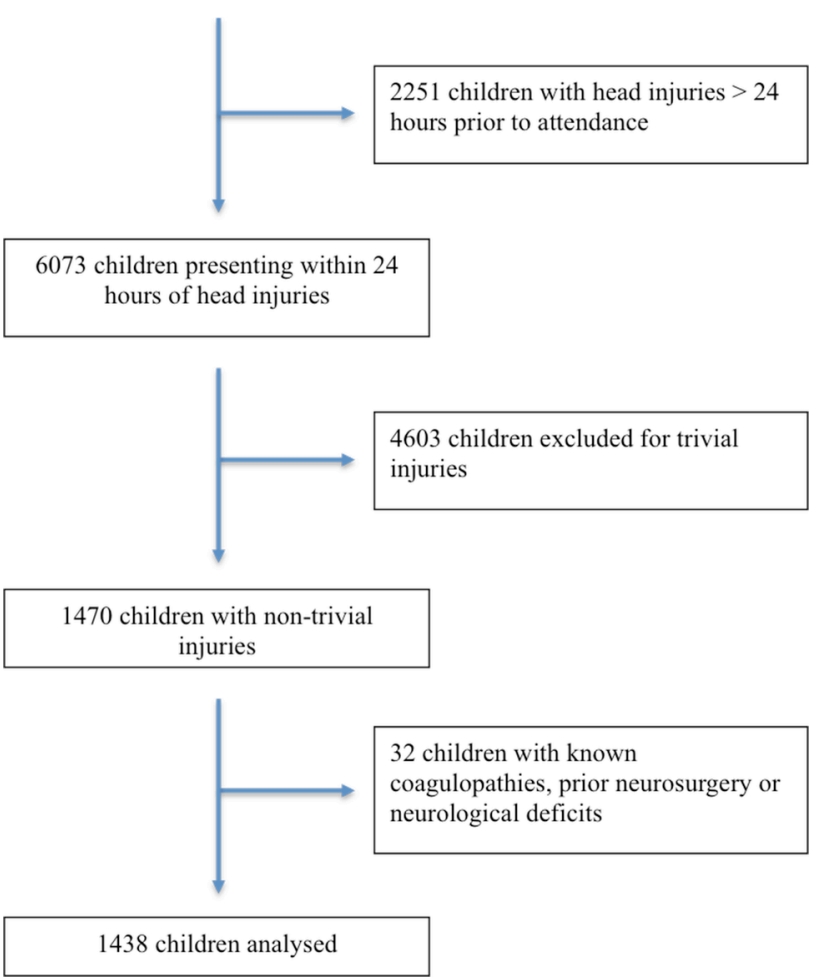

Figure 2 Flow diagram of patients included for analysis.

\section{RESULTS}

A total of 1438 children met the inclusion criteria (figure 2). 953 children (66.3\%) were male and the median age was 5.0 years (IQR 1.0-10.0). 1000 children $(69.5 \%)$ were from high-income, $208(14.5 \%)$ were from upper middle-income and $230(16.0 \%)$ were from lower middle-income countries. (The number of patients analysed from each centre is described in online supplementary table 1 . The annual paediatric trauma attendance and number of trauma cases requiring hospitalisation in each centre are elaborated in online supplementary table 2). We did not have missing data for the primary mechanism of injury.

Falls were the most common mechanism of injury across all ages (957 or $66.6 \%)$. Specifically among 415 children less than 2 years old, most of the head injuries were a result of falls (344 or $82.9 \%$ ) that occurred in the home (299 or $72.0 \%)$ The median height of the fall in these young children was 0.7 metres (IQR 0.5-1.0). (table 1). Among all 310 children involved in road traffic injuries, 96 (31.0\%) were pedestrian injuries. Among vehicle occupants, motorcycle users and pedal cyclists $(\mathrm{n}=214)$, only 29 children $(13.6 \%)$ were restrained (referring to child car seats, seat belts or helmets), 48 (22.4\%) were not restrained and 137 children $(64.0 \%)$ did not have documentation on the use of established preventative measures. Among vehicle occupant injuries, 29/80 (36.3\%) involved airbag activations during the collision. 
Table 1 Intent and mechanism of injury among all head injured children

\begin{tabular}{|c|c|c|c|}
\hline & $\begin{array}{l}\text { Children }<2 \text { years old } \\
(n=415)\end{array}$ & $\begin{array}{l}\text { Children } 2 \text { years old and } \\
\text { above }(n=1023)\end{array}$ & $\mathrm{p}$ value \\
\hline \multicolumn{4}{|l|}{ Intent of Injury, n (\%) } \\
\hline Unintentional & $397(95.7)$ & $980(95.8)$ & \\
\hline Assault - Child Abuse & $6(1.4)$ & $9(0.9)$ & \\
\hline Assault - Others & $1(0.2)$ & $13(1.3)$ & \\
\hline Intentional Self-Harm & $0(0.0)$ & $1(0.1)$ & \\
\hline Unknown & $11(2.7)$ & $20(2.0)$ & 0.268 \\
\hline \multicolumn{4}{|l|}{ Primary Mechanism of Injury, n (\%) } \\
\hline Fall & $344(82.9)$ & $613(59.9)$ & \\
\hline Road Traffic Injury & $46(11.1)$ & $264(25.8)$ & \\
\hline Struck by Object or Person & $15(3.6)$ & $102(10.0)$ & \\
\hline Sports Injury & $0(0.0)$ & $25(2.4)$ & \\
\hline Gun Shot & $0(0.0)$ & $2(0.2)$ & \\
\hline Others & $10(2.4)$ & $13(1.3)$ & $<0.001$ \\
\hline \multicolumn{4}{|l|}{ Among Road Traffic Injuries: Type of Road User, n (\%) } \\
\hline Total & $46(100.0)$ & $264(100.0)$ & \\
\hline Pedestrian & $10(21.7)$ & $86(32.6)$ & \\
\hline Motorcyclist & $7(15.2)$ & $75(28.4)$ & \\
\hline Vehicle Occupant & $26(56.5)$ & $54(20.5)$ & \\
\hline Pedal Cyclist & $3(6.5)$ & $45(17.0)$ & \\
\hline Unknown & $0(0)$ & $4(1.5)$ & $<0.001$ \\
\hline \multicolumn{4}{|l|}{ Object involved in Injury, n (\%) } \\
\hline Ground Surface & $87(21.0)$ & $294(28.7)$ & \\
\hline Land Transport/Means of Land Transport & $39(9.4)$ & $210(20.5)$ & \\
\hline Furniture & $128(30.8)$ & $94(9.2)$ & \\
\hline Building Component or Fitting & $60(14.5)$ & $135(13.2)$ & \\
\hline Animal, Plant or Person & $34(8.2)$ & $111(10.9)$ & \\
\hline Equipment for Sports or Recreational Activity & $1(0.2)$ & $67(6.5)$ & \\
\hline Infant or Child Care Product & $34(8.2)$ & $17(1.7)$ & $<0.001$ \\
\hline \multicolumn{4}{|l|}{ Location of Injury, n (\%) } \\
\hline Home & $299(72.0)$ & $351(34.3)$ & \\
\hline Street, Highway or Road & $43(10.4)$ & $276(27.0)$ & \\
\hline School & $10(2.4)$ & $169(16.5)$ & \\
\hline Public Playground or Amusement Park & $8(1.9)$ & $61(6.0)$ & \\
\hline Sports or Athletics Areas & $1(0.2)$ & $50(4.9)$ & $<0.001$ \\
\hline
\end{tabular}

Children 2 years old and above with head injuries were more likely to be involved in a road traffic injury (264, $25.8 \%$ ), compared with children younger than 2 years old $(46,11.1 \%)$. There was no statistically significant difference in the intent of injury between children younger than 2 years old and those 2 years and above $(\mathrm{p}=0.268)$. Table 2 shows the physical examination findings and outcomes for children in our study. Head-injured children 2 years and older were more likely to have a CT head performed compared with younger children $(\mathrm{p}<0.001)$. Among children 2 years and above, 301 (29.4\%) had a positive CT head, as compared with 134 (32.3\%) among those less than 2 years $(\mathrm{p}=0.284)$.

Eighty-five patients $(5.9 \%)$ were documented to have polytrauma, among whom intra-thoracic and long bone fractures were the most common (each 27 patients, or $1.9 \%)$. 279 children (19.4\%) required admission to higher acuity care units (intensive care or high dependency) after stabilisation in the ED. Among 115 children who underwent neurosurgery, $75(65.2 \%)$ had a craniotomy, $55(47.8 \%)$ had their intracranial bleeds evacuated and $17(14.8 \%)$ underwent elevation of depressed skull 
Table 2 Physical examination and outcome measures

\section{Children $<2$ years old \\ Children 2 years old and above}

$(n=415)$

$(n=1023)$

p value

\begin{tabular}{|c|c|c|c|}
\hline \multicolumn{4}{|l|}{ Presenting GCS, n (\%) } \\
\hline GCS 14-15 & $342(82.4)$ & $837(81.8)$ & \\
\hline GCS 8-13 & $24(5.8)$ & $91(8.9)$ & \\
\hline \multicolumn{4}{|l|}{ Physical Examination Findings, n (\%) } \\
\hline Contusion or Hematoma & $172(41.4)$ & $353(34.5)$ & \\
\hline Palpable Skull Fracture & $33(8.0)$ & $75(7.3)$ & \\
\hline Laceration & $15(3.6)$ & $93(9.1)$ & 0.011 \\
\hline CT Brain Performed, n (\%) & $187(45.1)$ & $660(64.5)$ & $<0.001$ \\
\hline Endotracheal Intubation, n (\%) & $55(13.3)$ & $114(11.1)$ & 0.278 \\
\hline ICU/HD† Admissions & $88(21.2)$ & $191(18.7)$ & \\
\hline Transfer to Operating Theatre & $2(0.5)$ & $33(3.2)$ & \\
\hline Transfer to Other Medical Centres & $8(1.9)$ & $18(1.8)$ & $<0.001$ \\
\hline Neurosurgical Intervention, n (\%) & $31(7.5)$ & $84(8.2)$ & 0.594 \\
\hline Death, $\mathrm{n}(\%)$ & $25(6.0)$ & $30(2.9)$ & 0.012 \\
\hline Hospital LOS* (in days) for Admitted Patients, & $1.0(1.0-2.0)$ & $1.0(1.0-4.0)$ & $<0.001$ \\
\hline
\end{tabular}

median (IQR)

*LOS - Length of Stay

†ICU/HD - Intensive Care Unit/High Dependency

ED, emergency department; GSC, Glasgow Coma Scale.

fractures. Thirty children $(2.9 \%) 2$ years and older died, compared with $25(6.0 \%)$ who were younger than 2 years old $(p=0.012)$. The median days of death post injury was 3 days (IQR 1.0-7.0). 19 children (34.5\%) who died were documented to have polytrauma, mainly intra-thoracic injuries (seven patients, $12.7 \%$ ). Specifically among the 15 children subject to child abuse, 5 (33.3\%) required intubation, $4(26.7 \%)$ received neurosurgical intervention and two children $(13.3 \%)$ died. The median age of the abused child was 7 years (IQR 0.0-14.0).

table 3 describes the primary mechanism of injury when stratified by GNI. Falls comprised a larger proportion of head injuries seen in the EDs of high-income countries (745, or $74.5 \%)$ compared with upper $(90,43.3 \%)$ and lower $(122,53.0 \%)$ middle-income countries. Conversely, road traffic injuries were responsible for a larger proportion of head injuries that presented to lower $(94,40.9 \%)$ and upper $(107,51.4 \%)$ middle-income countries, compared with high-income countries (109, 10.9\%). Severe and secondary outcomes stratified by GNI are shown in table 3. A greater proportion of children had the composite of severe outcomes in lower and upper middle-income countries compared with high-income countries $(28.4 \%$ and $58.2 \%$, vs $3.6 \%, \mathrm{p}<0.0001)$. This effect was seen for each of the individual severe outcomes of endotracheal intubation, neurosurgical intervention and death (table 3 ). When stratified by mechanism of injury, the length of hospital stay was significantly longer for children who were involved in road traffic injuries (median 3.0 days, IQR 1.0-7.0) compared with falls (median 1.0 day, IQR 1.0-2.0) $(\mathrm{p}<0.001)$.

Road traffic injuries were significantly associated with the severe outcomes of death, endotracheal intubation or need for neurosurgery (table 4). This remained statistically significant (adjusted OR, aOR 2.183, 95\% CI 1.448 to 3.293) after adjusting for age, gender, intent of injury and GNI. Intentional injuries were no longer statistically significant after adjustment (aOR 2.470, 95\% CI 0.839 to 7.272). In our study, centres in lower (aOR 8.769, 95\% CI 5.520 to 13.929 ) and upper (aOR 28.579, 95\% CI 17.986 to 45.412) middle-income countries were more likely to receive and care for children who subsequently had severe outcomes, compared with those from high-income countries.

\section{DISCUSSION}

After infancy, childhood injuries remain high on the list of killers in various parts of Asia. ${ }^{13}$ WHO recommends strengthening the role of the health sector in 
Table 3 Mechanism of injury, CT use, severe and secondary outcomes by Gross National Income (GNI)

\section{Primary Mechanism of injury}

\begin{tabular}{|c|c|c|c|c|c|}
\hline & $\begin{array}{l}\text { Lower Middle- } \\
\text { Income, n (\%) }\end{array}$ & $\begin{array}{l}\text { Upper Middle- } \\
\text { Income, n (\%) }\end{array}$ & $\begin{array}{l}\text { High-Income, } \\
\text { n (\%) }\end{array}$ & Total, n (\%) & $p$ value \\
\hline Total & 230 & 208 & 1000 & 1438 & \\
\hline Fall & $122(53.0)$ & $90(43.3)$ & $745(74.5)$ & $957(66.6)$ & $<0.001$ \\
\hline Traffic Injury & $94(40.9)$ & $107(51.4)$ & $109(10.9)$ & $310(21.6)$ & \\
\hline Struck by Person or Object & $5(2.2)$ & $8(3.8)$ & $104(10.4)$ & $117(8.1)$ & \\
\hline Sports Injury & $2(0.9)$ & $1(0.5)$ & $22(2.2)$ & $25(1.7)$ & \\
\hline Stab or Cut & $0(0.0)$ & $0(0.0)$ & $4(0.4)$ & $4(0.3)$ & \\
\hline Gun Shot & $2(0.9)$ & $0(0.0)$ & $0(0.0)$ & $2(0.1)$ & \\
\hline Others ${ }^{*}$ & $5(2.2)$ & $2(1.0)$ & $16(1.6)$ & $23(1.6)$ & \\
\hline \multicolumn{6}{|l|}{ CT Use } \\
\hline CT Use & $214(93.0)$ & $208(100.0)$ & $426(42.6)$ & $848(59.0)$ & $<0.001$ \\
\hline \multicolumn{6}{|l|}{ Severe Outcomes } \\
\hline Endotracheal Intubation & $49(21.4)$ & $97(46.6)$ & $23(2.3)$ & $169(11.8)$ & $<0.001$ \\
\hline Neurosurgical Intervention & $20(10.4)$ & $71(34.1)$ & $24(2.4)$ & 115 (8.2) & $<0.001$ \\
\hline Death & $13(5.7)$ & $35(16.8)$ & $7(0.7)$ & $55(3.8)$ & $<0.001$ \\
\hline \multicolumn{6}{|l|}{ Secondary Outcomes } \\
\hline Admitted to Hospital & $187(81.3)$ & $188(90.4)$ & $788(78.8)$ & $1163(80.9)$ & $<0.001$ \\
\hline Hospital Length of Stay, median (IQR) & $3.0(2.0-6.0)$ & $5.0(2.0-13.0)$ & $1.0(1.0-2.0)$ & $1.0(1.0-3.0)$ & $<0.001$ \\
\hline
\end{tabular}

*'Others' mechanism comprised primarily of cases where the mechanism of injuries could not be obtained or categorised from retrospective chart review.

evidence-based advocacy and service provision for victims of such trauma. ${ }^{14}$ This collaboration among participating PATOS centres enabled clinical childhood injury data across different centres in Asia to be analysed.

In our study, falls were the most common mechanism of injury, particularly among children $<2$ years old. Road traffic injuries, while less common than falls, were more likely to occur among children 2 years and older, and were significantly associated with severe outcomes. Children with head injuries who presented to the EDs of lower and upper middle-income countries were more likely to be involved in road traffic injuries and to suffer severe outcomes, compared with those in high-income countries.

Table 4 Logistic regression for death, intubation or neurosurgical intervention

\begin{tabular}{|c|c|c|}
\hline & Unadjusted OR (95\% Cl) & Adjusted OR (95\% Cl) \\
\hline Age & $0.988(0.960$ to 1.017$)$ & $0.968(0.932$ to 1.007$)$ \\
\hline Male Gender & $1.612(1.165$ to 2.231$)$ & 1.233 (0.832 to 1.828$)$ \\
\hline Fall & Referent & Referent \\
\hline Road Traffic Injury & 4.903 (3.574 to 6.726$)$ & 2.183 (1.448 to 3.293$)$ \\
\hline Others & 2.084 (1.016 to 4.277$)$ & 2.946 (1.200 to 7.227$)$ \\
\hline \multicolumn{3}{|l|}{ Intent } \\
\hline Unintentional & Referent & Referent \\
\hline Intentional & 2.956 (1.355 to 6.446$)$ & 2.470 (0.839 to 7.272$)$ \\
\hline Unknown & 0.802 (0.278 to 2.311$)$ & 1.252 (0.365 to 4.291$)$ \\
\hline \multicolumn{3}{|l|}{ Gross National Income } \\
\hline Upper Middle-Income & 37.240 (24.178 to 57.360$)$ & 28.579 (17.986 to 45.412$)$ \\
\hline Lower Middle-Income & $10.612(6.838$ to 16.471$)$ & 8.769 (5.520 to 13.929$)$ \\
\hline
\end{tabular}


Our findings on falls reinforce that of a national study from the United Kingdom. ${ }^{15}$ Falls among preverbal children occur mainly in the home, involving ground surfaces and furniture. Although most falls occur from a low height, they still result in physical injuries and urgent care attendances. This suggests the need to relook at home safety and caregiver awareness.

The association between road traffic injuries and severe outcomes emphasises that road safety remains a pressing public health concern in Asia. Road traffic legislation on the use of child restraints (child car seats and helmets) is variable among different countries in Asia. ${ }^{16}$ Even in countries with clear legislation on the use of child restraints, compliance has been found to be lacking. ${ }^{17}$ There was an extremely low rate of documented restraint use in this study. This highlights both the need for better injury surveillance and documentation, as well as improved adherence to safe road practices and enforcement of road traffic laws. ${ }^{18}{ }^{19}$ Specific concerns among motorcycle road users in Asia include the low rate of helmet use among children, ${ }^{20}$ overloading of motorcycles, ${ }^{21}$ and high risk behaviour among adolescents while racing. ${ }^{22} 23$

When stratified by GNI, a larger proportion of paediatric head injuries were attributed to falls in the PATOS centres from high-income countries. We postulate that this may be due to differences in healthcare delivery with lower acuity injuries from falls more likely to present to the EDs of high-income compared with middle-income countries. This is suggested by the different hospitalisation rate between centres when stratified by GNI (online supplementary table 2). The larger proportion of injuries attributed to road traffic collisions in middle-income countries could also be due to the absence of enforced legislation for safe road practices.

There were more deaths and severe in-hospital outcomes among lower and upper middle-income countries, despite a smaller total number of injuries. This effect persisted after adjusting for mechanism of injury. We postulate that severity of injury, pre-hospital care and accessibility to trauma centres with paediatric capabilities contribute to this effect. ${ }^{24}$ We did not collect data on interventional strategies for traumatic brain injuries in this study.

CT scan rates here are high compared with other studies. ${ }^{12}$ This was likely due to differences in case ascertainment, because we excluded mild cases that had symptom resolution. In our study, 258 children (17.9\%) had a GCS of 13 and below. There was a positive CT rate of $30.3 \%$ and a positive event rate (death, intubation or neurosurgery) of $15.4 \%$. Importantly, differences in healthcare settings were likely to contribute to the variability in CT rates, including individual hospital protocols and the availability of facilities to observe head injured children.

Our findings on child abuse build on previous reports that such injuries are associated with death and long term neurological compromise. ${ }^{25} 26$ Early clinical recognition is paramount for holistic care of the child, ${ }^{27}$ and such cases must be readily identified by emergency medicine providers acting as advocates for this vulnerable population. The median age of 7 years differs from another study where infants predominated among victims of child abuse. ${ }^{28}$ In our study, we recognise that child abuse cases were very few in number. These are likely to be under-diagnosed and under-reported in Asia. Important differences between centres include varying definitions for child abuse, the presence (or absence) of a multidisciplinary team for onward referral, and variable child protection measures formally stipulated by state law. Moving forward, we recognise the need to gain common ground, including the multi-disciplinary assessment required for accurate case definitions. ${ }^{29}$

We recognise the following limitations of this study. We have compiled data across different populations with varying healthcare delivery systems. In this retrospective review, details surrounding the use of restraints were missing in some countries that do not have routine surveillance data. The impact of different countries' road traffic laws on the rate and type of injuries were not explored here. We recognise that hospital-based studies are limited and should extend to more systematic surveillance in each country that can translate to practical safety measures. ${ }^{30}$ We were not able to report detailed neurological assessments for both in-hospital and out-of-hospital outcomes because availability of these data varied between centres. The above highlight the dire need for improved documentation that can inform policies and injury prevention strategies in Asia. Specifically, individual factors including injury severity scores and systemic factors including pre-hospital systems, accessibility to trauma care and interventional strategies for paediatric head injuries must be better documented.

To our knowledge, this is the first attempt to collate paediatric head injury surveillance data from different centres in Asia. Road traffic injuries continue to account for death and severe injuries, especially in middle-income countries. Importantly, this paves the way for further prospective surveillance studies to be performed among the PATOS centres.

\section{Author affiliations}

'Department of Emergency Medicine, KK Women's and Children's Hospital, Singapore, Singapore

${ }^{2}$ Duke-NUS Medical School, Singapore

${ }^{3}$ Department of Emergency Medicine, Aga Khan University Hospital, Karachi, Pakistan

${ }^{4}$ Department of Pediatric Emergency Medicine, Institute of Child Health and Hospital for Children, Madras Medical College, Chennai, Tamilnadu, India

${ }^{5}$ Department of Emergency Medicine, Dongguk University Ilsan Hospital, School of Medicine, Dongguk University, Seoul, Republic of Korea

${ }^{6}$ Department of Emergency Medicine, Beijing Children's Hospital, Capital Medical University, Beijing, China

${ }^{7}$ Department of Emergency and Trauma, Sungai Buloh Hospital, Selangor, Malaysia ${ }^{8}$ Department of Emergency, Hue Central Hospital, Hue, Vietnam

${ }^{9}$ Department of Paediatrics, Yong Loo Lin School of Medicine, National University of Singapore, Singapore

${ }^{10}$ Khoo Teck Puat-National Children's Medical Institute,, National University Health System, Singapore

${ }^{11}$ Department of Emergency Medicine, Singapore General Hospital, Singapore 
${ }^{12}$ Health Services and Systems Research, Duke-NUS Medical School, Singapore

Acknowledgements We would like to thank the following persons for their contribution in design and data collection: Professor Sang Do Shin (College of Medicine Seoul National University), Ms Dianna Sri Dewi (KK Women's and Children's Hospital), Dr Emaduddin Siddiqui, Dr Fareed Ahmed, Ms Rubaba Naeem and Ms Muniba Shah (Aga Khan University Hospital), Dr Deepa J (Madras Medical College), Dr Seung Chul Lee (Dongguk University Ilsan Hospital), Dr Wu Jie (Beijing Children's Hospital), Dr Rebecca Choy Xin Yi and Dr Yap Hsiao Ling (Sungai Buloh Hospital), Dr Hoang Pito and Dr Ton That Hoang Quy (Hue Central Hospital). We would also like to thank Fu Sheng and Chris John Lalonde for administering the online electronic form.

Contributors CSL, URK, IS, and MEHO made substantial contributions to the conception and design of the work. CSL, URK, IS, SJS, WQ, SFJ, HTAQ, and CSY contributed in the data acquisition. CSL, URK, IS, CSY and MEHO contributed in the analysis and interpretation of the data. All authors revised it critically for important intellectual content and approved of the final version to be published.

Funding This work was supported by the Singapore SingHealth DUKE-NUS Paediatrics Academic Clinical Programme.

Competing interests None declared.

Patient consent This is a retrospective study and waiver of informed consent was granted by the Institutional Review Board.

Ethics approval Singapore SingHealth Centralised Institutional Review Board (CIRB, E).

Provenance and peer review Not commissioned; externally peer reviewed.

Data sharing statement There is no additional unpublished data from this study available currently.

Open Access This is an Open Access article distributed in accordance with the Creative Commons Attribution Non Commercial (CC BY-NC 4.0) license, which permits others to distribute, remix, adapt, build upon this work non-commercially, and license their derivative works on different terms, provided the original work is properly cited and the use is non-commercial. See: http://creativecommons.org/ licenses/by-nc/4.0/

(c) Article author(s) (or their employer(s) unless otherwise stated in the text of the article) 2017. All rights reserved. No commercial use is permitted unless otherwise expressly granted.

\section{REFERENCES}

1. Johnston BD, Ebel BE. Child injury control: trends, themes, and controversies. Acad Pediatr 2013;13:499-507.

2. Streatfield PK, Khan WA, Bhuiya A, et al. Mortality from external causes in Africa and Asia: evidence from INDEPTH Health and Demographic Surveillance System Sites. Glob Health Action 2014;7:25366.

3. Wismans J, Skogsmo I, Nilsson-Ehle A, et al. Commentary: status of road safety in Asia. Traffic Inj Prev 2016;17:217-25.

4. Chong SL, Barbier S, Liu N, et al. Predictors for moderate to severe paediatric head injury derived from a surveillance registry in the emergency department. Injury 2015;46:1270-4.

5. Chevignard M, Francillette L, Toure $\mathrm{H}$, et al. Academic outcome, participation and health-related quality of life following childhood severe traumatic brain injury: results of a prospective longitudinal study: the seven-year follow-up of the TGE cohort. Ann Phys Rehabil Med 2016;59:e133.

6. Treble-Barna A, Zang H, Zhang N, et al. Long-Term Neuropsychological Profiles and their role as mediators of adaptive functioning after traumatic brain Injury in Early Childhood. $J$ Neurotrauma 2017:34.

7. Yang LY, Huang CC, Chiu WT, et al. Association of traumatic brain injury in childhood and attention-deficit/hyperactivity disorder: a population-based study. Pediatr Res 2016;80.
8. Pan asian trauma outcomes study (PATOS). http://lems.re.kr/eng/ patos-research/ (assessed 25 Mar 2017).

9. World Economic Situation Prospects. http://www.un.org/en/ development/desa/policy/wesp/wesp_current/2016wesp_full_en.pdf (assessed 25 Mar 2017).

10. ICECI, International classification of External Causes of Injuries. http://www.whofic.nl/en/Family_of_International_Classifications/ Related_classifications/ICECl_International_Classification_of_ External_Causes_of_Injuries (assessed 25 Mar 2017).

11. Chong SL, Chew SY, Feng JX, et al. A prospective surveillance of paediatric head injuries in Singapore: a dual-centre study. BMJ Open 2016;6:e010618.

12. Kuppermann N, Holmes JF, Dayan PS, et al. Identification of children at very low risk of clinically-important brain injuries after head trauma: a prospective cohort study. Lancet 2009;374:1160-70.

13. Wang Y, Du M, Hao Z, et al. Causes of death in Children Aged < 15 years in the Inner Mongolia Region of China, 2008-2012. Glob J Health Sci 2016;8:56176.

14. World Health Organization. Regional Office for the Western Pacific Bureau. http://www.wpro.who.int/about/regional_committee/66/ documents/wpr rc66 07 violence and injury prevention.pdf?ua=1 (assessed 25 Mar 2017).

15. Trefan L, Houston R, Pearson G, et al. Epidemiology of children with head injury: a national overview. Arch Dis Child 2016;101:527-32.

16. Global status report on road safety 2015. http://www.who.int/ violence_injury_prevention/road_safety_status/2015/en/ (assessed 25 Mar 2017).

17. Chong SL, Tyebally A, Chew SY, et al. Road traffic injuries among children and adolescents in Singapore - Who is at greatest risk? Accid Anal Prev 2017;100:59-64.

18. Lee LK, Farrell CA, Mannix R. Restraint use in motor vehicle crash fatalities in children 0 year to 9 years old. $J$ Trauma Acute Care Surg 2015;79(3 Suppl 1):S55-60.

19. Lee LK, Monuteaux MC, Burghardt LC, et al. Motor Vehicle Crash fatalities in States with Primary Versus Secondary Seat Belt Laws: a Time-Series analysis. Ann Intern Med 2015;163:184-90.

20. Fong MC, Measelle JR, Dwyer JL, et al. Rates of motorcycle helmet use and reasons for non-use among adults and children in Luang Prabang, Lao People's Democratic Republic. BMC Public Health 2015;15:970.

21. Oxley J, Ravi MD, Yuen J, et al. Identifying contributing factors to fatal and serious injury motorcycle collisions involving children in Malaysia. Ann Adv Automot Med 2013;57:329-36.

22. Liang CC, Liu HT, Rau CS, et al. Motorcycle-related hospitalization of adolescents in a level I trauma center in Southern Taiwan: a crosssectional study. BMC Pediatr 2015;15:105.

23. Tongklao A, Jaruratanasirikul S, Sriplung H. Risky behaviors and helmet use among young adolescent motorcyclists in Southern Thailand. Traffic Inj Prev 2016;17:80-5.

24. McCarthy A, Curtis K, Holland AJ. Paediatric trauma systems and their impact on the health outcomes of severely injured children: an integrative review. Injury 2016;47:574-85.

25. Thielen FW, Ten Have M, de Graaf R, et al. Long-term economic consequences of child maltreatment: a population-based study. Eur Child Adolesc Psychiatry 2016;25:1297-305.

26. Ward A, locono JA, Brown S, et al. Non-accidental Trauma Injury patterns and outcomes: a single institutional experience. Am Surg 2015;81:835-8.

27. Shaahinfar A, Whitelaw KD, Mansour KM. Update on abusive head trauma. Curr Opin Pediatr 2015;27:308-14.

28. Davies FC, Coats TJ, Fisher R, et al. A profile of suspected child abuse as a subgroup of major trauma patients. Emerg Med $J$ 2015;32:921-5.

29. Maguire SA, Kemp AM, Lumb RC, et al. Estimating the probability of abusive head trauma: a pooled analysis. Pediatrics 2011;128:e550-64.

30. Karkee R, Lee AH. Epidemiology of road traffic injuries in Nepal, 2001-2013: systematic review and secondary data analysis. BMJ Open 2016;6:e010757. 